\title{
In vitro analysis of the proliferative capacity and cytotoxic effects of ex vivo induced natural killer cells, cytokine-induced killer cells, and gamma-delta T cells
}

\author{
Chao Niu ${ }^{\dagger}$, Haofan $\mathrm{Jin}^{\dagger}$, Min Li, Jianting Xu, Dongsheng Xu, Jifan Hu, Hua He, Wei Li ${ }^{*}$ and Jiuwei Cui ${ }^{*}$
}

\begin{abstract}
Background: Recent studies have focused on the significant cytotoxicity of natural killer (NK) cells, cytokine-induced killer (CIK) cells, and gamma-delta $(\gamma \delta)$ T cells in tumor cells. Nevertheless, the therapeutic features of these cell types have not been compared in the literature. The aim of this study was to evaluate the feasibility of activation and expansion of NK, CIK, and $\gamma \delta \mathrm{T}$ cells from cancer patients in vitro, and to clarify the differences in their antitumor capacities.

Methods: NK, CIK, and $\gamma \delta$ T cells were induced from the peripheral blood mononuclear cells of 20 cancer patients by using specific cytokines. Expression of CD69, NKG2D, CD16, granzyme B, perforin, IFN- $\gamma$, and IL-2 was measured by flow cytometry. Cytokine production and cytotoxicity were analyzed by enzyme-linked immunosorbent assay and Calcein-AM methods.

Results: NK cell proliferation was superior to that of CIK cells, but lower than that of $\gamma \delta T$ cells. NK cells had a much stronger ability to secrete perforin, granzyme B, IFN- $\gamma$, and IL-2 than did CIK and $\gamma \delta$ T cells, and imparted significantly higher overall cytotoxicity.

Conclusions: Expanded NK cells from cancer patients are the most effective immune cells in the context of cytokine secretion and anti-tumor cytotoxicity in comparison to CIK and $\gamma \delta T$ cells, making them an optimal candidate for adoptive cellular immunotherapy.
\end{abstract}

Keywords: Natural killer cells, Cytokine-induced killer cells, Gamma-delta T cells, Cytotoxicity

\section{Background}

Cellular immunity plays an essential role in anti-tumor activity. Immunocyte activity is often compromised in tumor patients, due to the inhibitory tumor environment. Therefore, numerous preliminary studies have demonstrated the safety and efficacy of adoptive cellular immunotherapy (ACI) - consisting of ex vivo expansion and activation of patient immunocytes followed by reinfusion [1]. ACI has become a promising, innovative strategy for personalized cancer therapy [2]. Due to the complexity of immune escape-such as antigen loss, MHC class I down-regulation, and the expression of inhibitory molecules-specific immune cells such as cytotoxic $\mathrm{T}$ lymphocytes (CTL) have limited utility in cancer

\footnotetext{
* Correspondence: dwweili@163.com; jiuweicui@163.com

${ }^{\dagger}$ Equal contributors

Cancer Center, the First Hospital of Jilin University, 71 Xinmin Street,

Changchun 130021, China
}

therapeutics [3]. Non-specific immune effector cells such as natural killer (NK) cells, cytokine-induced killer (CIK) cells, and gamma-delta $(\gamma \delta)$ T cells have better potential, since they have no $\mathrm{MHC}$ restriction, contribute to front-line anti-tumor surveillance, and bridge the gap between innate and adaptive immunity $[4,5]$. These cell types share many common mechanisms, including NKG2D and perforin-mediated cytotoxicity, and cytokine secretion [6-8]. However, each of them has unique features, and their therapeutic effects have been shown in ex vivo studies and clinical trials.

NK cells, which are large, granular $\mathrm{CD}^{-} \mathrm{CD}^{-} 6^{+}$lymphocytes, can be rapidly activated to spontaneously attack certain abnormal cells in the body, particularly cancerous or virusinfected cells $[9,10]$. Individuals who have low NK cell activity are at increased risk of developing cancer [11, 12]. Several clinical trials have confirmed the therapeutic benefit and safety of NK cell adoptive infusion [13, 14]. CIK cells are heterogeneous. The main effector cells are $\mathrm{CD}^{+} \mathrm{CD} 56^{+} \mathrm{T}$ cells, which 
exhibit both the powerful anti-tumor effect of $\mathrm{T}$ cells and the non-MHC restriction of NK cells [15]. Recent clinical studies have indicated that CIK cells can significantly improve progression-free survival, overall survival, and effective clinical response in cancer patients [16]. In addition to NK and CIK cells, $\gamma \delta$ T cells may display the same cytotoxicity as NK and CIK cells, and act as antigenpresenting cells.

For the past decade, ACI with NK, CIK, and $\gamma \delta$ T cells has been a primary focus in cancer therapy, especially for hematological malignancies such as leukemia, lymphoma, and multiple myeloma [17-20]. However, there has been no direct comparison of these cell types. In this study, we evaluated the feasibility of in vitro expansion of each immune cell type and compared their antitumor activity against various forms of hematological cancers with the aim of providing in vitro evidence for their use in ACI cancer therapies.

\section{Results}

\section{Cell quantification and expansion}

$\mathrm{NK}, \mathrm{CIK}$, and $\gamma \delta$ T cells were induced from the PBMCs of 20 cancer patients. After 14 days induction, immunocyte viability exceeded $85 \%$ without contamination. All cells were able to propagate in vitro: NK cells to a median of 359 -fold (250-669-fold, $n=20$ ), CIK cells to 253-fold (120-621-fold, $n=20$ ), and $\gamma \delta \mathrm{T}$ to 550-fold (159-879-fold, $n=20) ; \gamma \delta \mathrm{T}$ cells had the strongest amplification ability (Fig. 1).

After induction and expansion, the percentage of expanded NK $(r=0.339, p=0.001)$, CIK $(r=0.358, p=0.003)$, and $\gamma \delta \mathrm{T}(r=0.344, p=0.004)$ cells showed a slight positive correlation with their percentage in the patients' blood (Spearman's test). These data suggest the percentage of

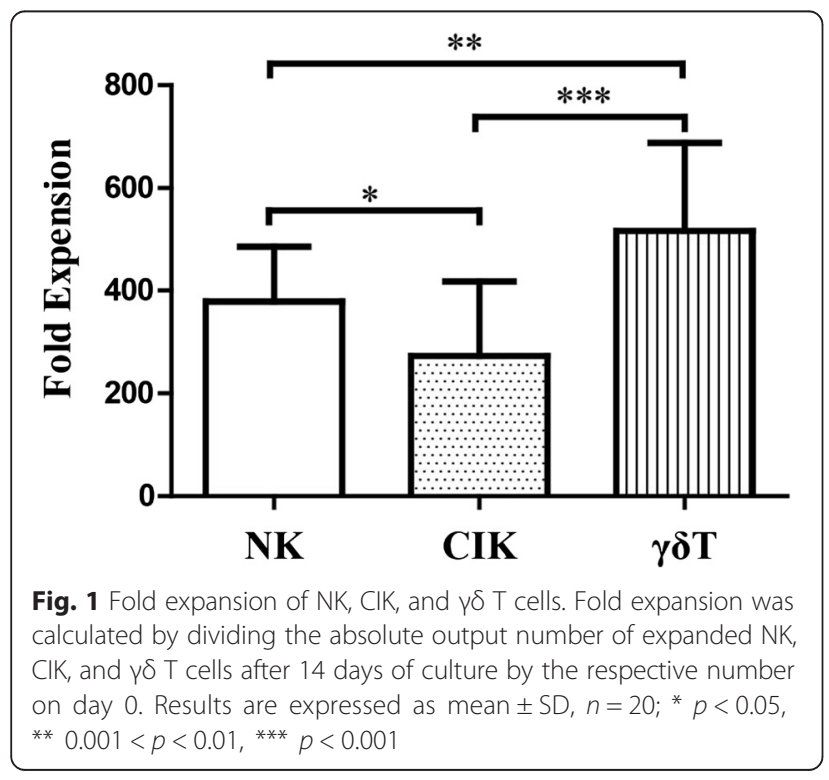

immune cells in the patients' blood likely has little effect on the ex vivo induction of these immune cell types, further demonstrating the stability and broad applicability of our methods.

\section{Immunophenotyping of expanded immune cells}

The percentages of $\mathrm{NK}\left(\mathrm{CD}_{56}{ }^{+} \mathrm{CD} 3^{-}\right), \gamma \delta \mathrm{T}\left(\mathrm{V} \gamma 9^{+} \mathrm{CD} 3^{+}\right)$, and $\mathrm{CIK}\left(\mathrm{CD}^{+} 6^{+} \mathrm{CD}^{+}\right)$cells before and after induction were $16.1(1.7-29.7)$ vs. 79.7 (62.1-98.4), $4.4(0.9-10.2)$ vs. $65.9(40.2-98.2)$ and $12.7 \%(1.6-21.1 \%)$ vs. $35.4 \%$ (16.3-55.6\%), respectively. A portion of $\gamma \delta \mathrm{T}$ cells (10.2-45.9\%) was CD56-positive, and nearly no expression of CD4 or CD8 was observed in the population. However, the majority of CIK cells were CD8-positive (Fig. 2).

NK and CIK cells in patient blood rarely express CD69, but $\gamma \delta \mathrm{T}$ cells exhibited high expression of this marker. After induction and expansion, activated NK and CIK cells expressed much higher levels of CD69. However, there was only a slight increase in CD69 expression on $\gamma \delta$ T cells before and after induction. After NKG2D induction, only $\gamma \delta$ T cells showed a very strong increase (Fig. 3a). However, CD16 expression differed between immune cell types. NK cells had the highest CD16 expression at $78.7 \%$ (50.2-98.2 \%). In contrast, some of the $\mathrm{CD}^{+}{ }^{+} \mathrm{CD} 56^{+} \mathrm{CIK}$ cells $(30.7,6.9-59.6)$ and $\gamma \delta$ T cells $(11.7 \%, 2.6-37.7 \%)$ were also CD16-positive (Fig. 3b). After induction, inhibitory KIR CD158a and CD158b on NK cells were down-regulated. Representative results from one of these patients are shown in Fig. 3c.

All three induced immune cells expressed perforin. NK cells showed much higher perforin production than the other two expanded immune cell types. $\gamma \delta \mathrm{T}$ cells showed slightly higher perforin production than CIK cells (Fig. 4a). Almost all NK $(97.3 \pm 2.2)$ and CIK $(94.8 \% \pm 5.2 \%)$ cells and a majority of $\gamma \delta \mathrm{T}$ cells $(72.3 \% \pm 13.1 \%)$ were granzyme B-positive. However, NK cells yielded the strongest expression of granzyme B (Fig. 4b).

\section{Cytokine secretion of the expanded cells}

Nearly all of the expanded NK cells and half of the CIK and $\gamma \delta$ T cells were IFN- $\gamma$-positive. About $40 \%$ of the NK cells were IL-2-positive, while only a small portion of CIK and $\gamma \delta$ T cells were positive for IL-2 (Fig. 5a). NK cells were much more efficient secretors of IFN- $\gamma$ and IL-2 than were CIK and $\gamma \delta$ T cells (Fig. 5b). Subsets of NK cells or CIK and $\gamma \delta$ T cells secreted a very high level of IFN- $\gamma$, yet only a small amount of IL-2 was detected in the supernatant of the CIK and $\gamma \delta$ T cells. No differences in INF- $\gamma$ and IL-2 secretion were observed between CIK and $\gamma \delta$ T cells. Very low levels of IL-4, IL-6, and IL10 were detected in the supernatants of $\mathrm{NK}, \mathrm{CIK}$, and $\gamma \delta$ T cells (Fig. 4b). 


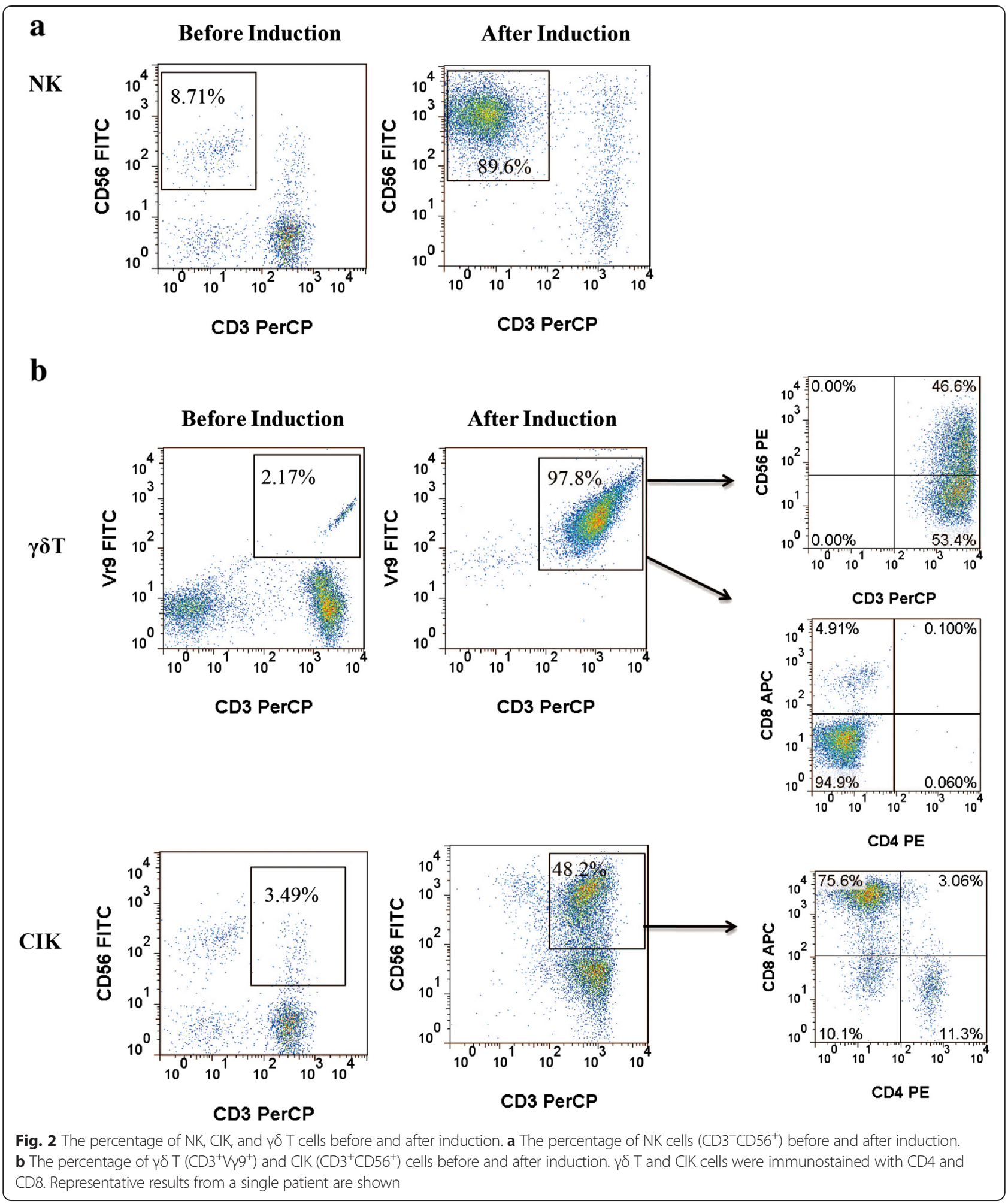

Cytotoxicity of expanded immune cells against hematologic malignancies cell lines

We compared the cytotoxicity of NK, CIK, and $\gamma \delta \mathrm{T}$ cells against hematologic tumors, as bulk expanded immune cells tested in the Calcein-AM assay showed substantial cytotoxic capacity. NK cells exhibited the most significant cytotoxicity in K562 (Fig. 6a), NB4 (Fig. 6b), HL-60 (Fig. 6d), and U266 (Fig. 6e) cells. Both NK and $\gamma \delta \mathrm{T}$ cells produced stronger cytotoxic effects against Jurkat cells than CIK cells (Fig. 6c). Although all 


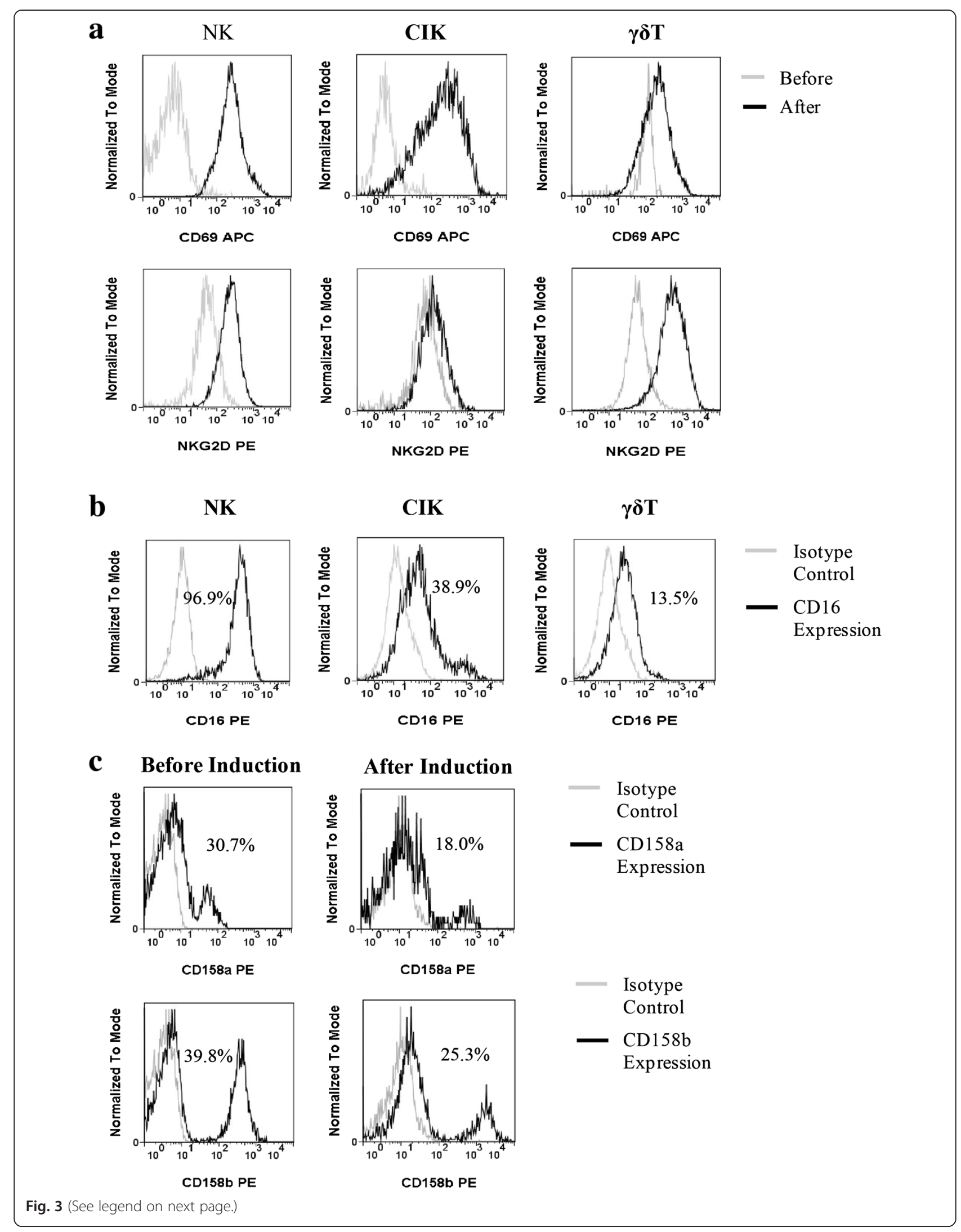


(See figure on previous page.)

Fig. 3 Expression of CD69, NKG2D, and KIR on induced immune cells. a The expression of CD69 and NKG2D were analyzed by flow cytometry (gray histogram). CD69 and NKG2D expression peaks are shifted to the right in expanded cells versus pre-induction cells (black histogram). $\mathbf{b}$ Expression of CD16; gray histograms depict isotype controls. c Expression of KIR (CD158a and CD158b) on NK cells before and after induction. Gray histograms depict isotype controls and the black histogram depicts the specific antibody. Data from one representative patient is shown

three expanded cell types exhibited limited cytotoxicity against Raji cells compared to other target cells, NK cells exerted the strongest antitumor activity (Fig. 6f). Interestingly, the addition of rituximab significantly enhanced Raji lysis by all cell types; however, NK cells continued to show a greater synergistic cytotoxicity in Raji cells with rituximab in comparison to $\mathrm{CIK}$ and $\gamma \delta \mathrm{T}$ cells. Nevertheless, there were no notable differences in cytotoxicity against Raji cells between CIK and $\gamma \delta$ T cells in the presence of rituximab (Fig. 7).

\section{Discussion}

Although many studies have shown the importance of $\mathrm{NK}, \mathrm{CIK}$, and $\gamma \delta \mathrm{T}$ cells in the prevention of tumor relapse and metastasis in mice and humans [8, 21, 22], few studies have directly compared their cytotoxic effects to identify which would be the optimal candidate for clinical application. There are many issues to be considered prior to clinical application, including the number of introduced cells, the feasibility of in vitro expansion, and their respective anti-tumor activities.
Obtaining an adequate number of immune cells is a key challenge for ACI application in a clinical setting [23]. Studies indicate that sufficient numbers of CIK and $\gamma \delta \mathrm{T}$ cells can be obtained by current methods [3, 20]; however, methods for the expansion of NK cells in vitro have being investigated by using feeder cells, including irradiated allogenic PBMCs [24], K562 cells [25], and Epstein-Barr virus-transformed lymphoblastoid cell lines [19]. Although these NK cell infusions are well tolerated and partially effective, current methods for NK cell preparation involve complex separation protocols and often require ethical approval that render them expensive and sub-optimal or unfeasible for large-scale clinical studies [26]. To overcome these disadvantages, we examined whether the use of CD16 antibody-coated flasks could be used in place of feeder cells. Our studies demonstrate that a substantial number of NK cells could be generated, ranging from 250-669-fold expansions, after 14 days induction and culture. Importantly, this is comparable to the yields of feeder-cell methods [19]. In addition to NK cells, we amplified CIK and $\gamma \delta$ T cells in
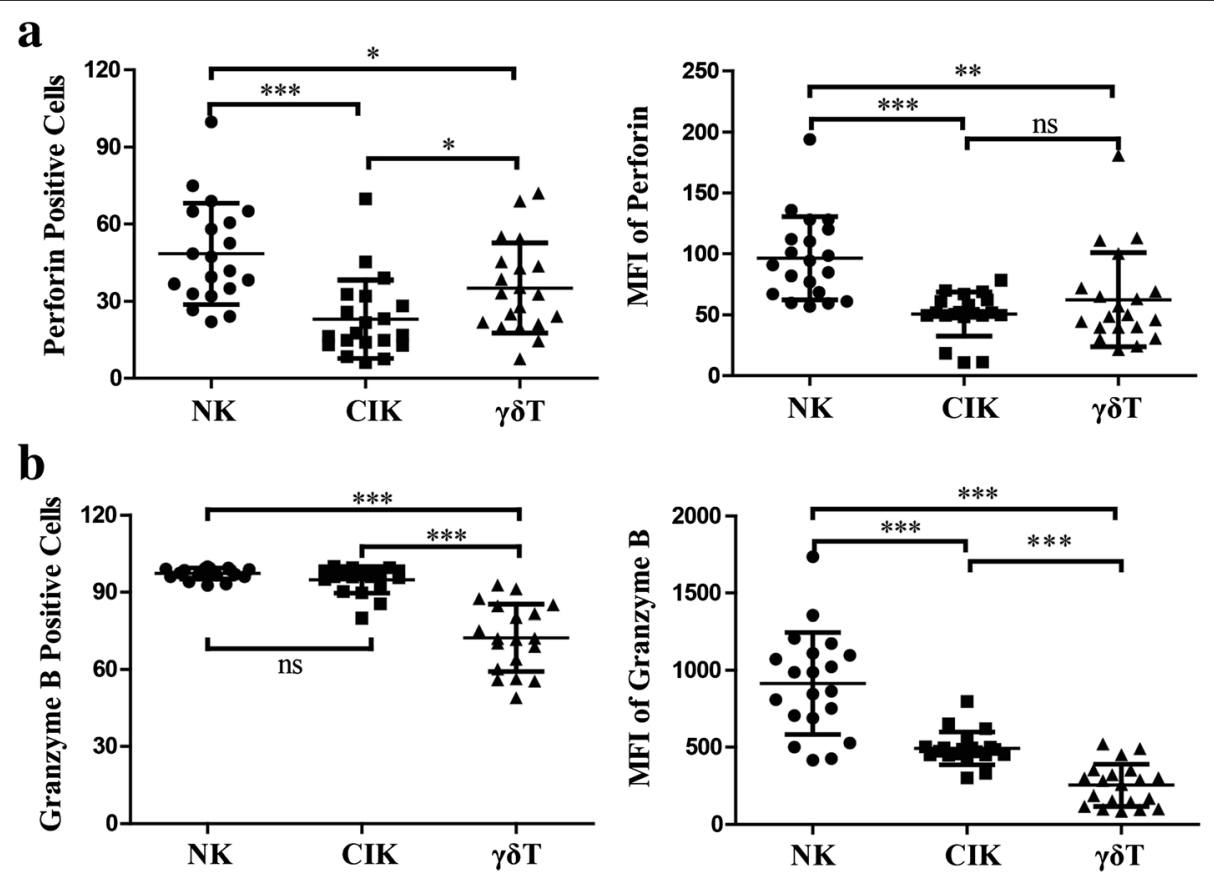

Fig. 4 Perforin and granzyme B production in expanded NK, CIK, and $\gamma \delta T$ cells. Three types of immune cells from twenty cancer patients were harvested after 14 days induction in vitro. NK and CIK cells were stained with mAbs to CD3 and CD56, and $\gamma \delta$ T cells were stained with CD3 and Vy9. After fixation and permeabilization, cells were stained for perforin and granzyme B using specific conjugated anti-human cytokine mAbs. a Perforin-positive cells and mean fluorescence intensity (MFI) of NK, CIK, and $\gamma \delta$ T cells. b Granzyme B-positive cells and MFI of NK, CIK, and $\gamma \delta T$ cells. Results are expressed as mean $\pm \mathrm{SD}, n=20 .{ }^{*} p<0.05,{ }^{* *} 0.001<p<0.01,{ }^{* * *} p<0.001$, ns $p>0.05$ 

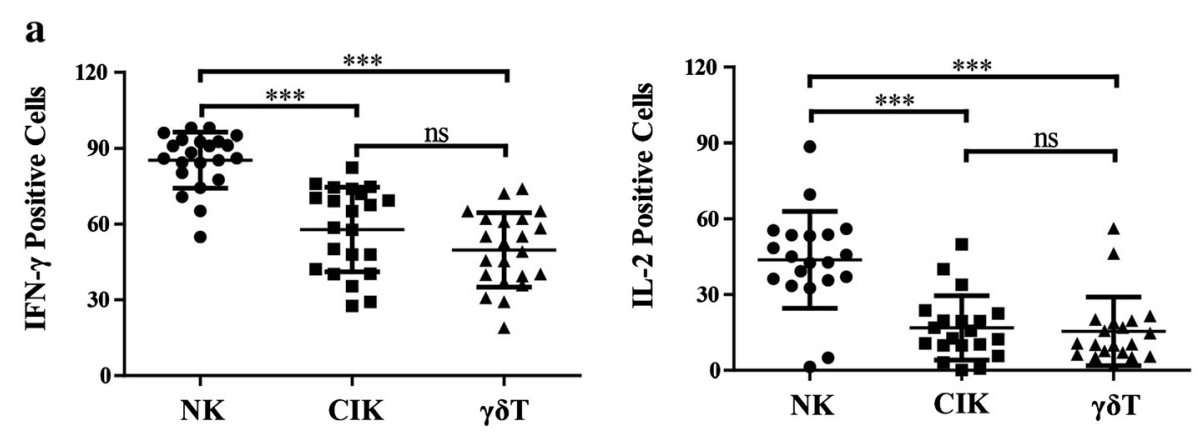

b
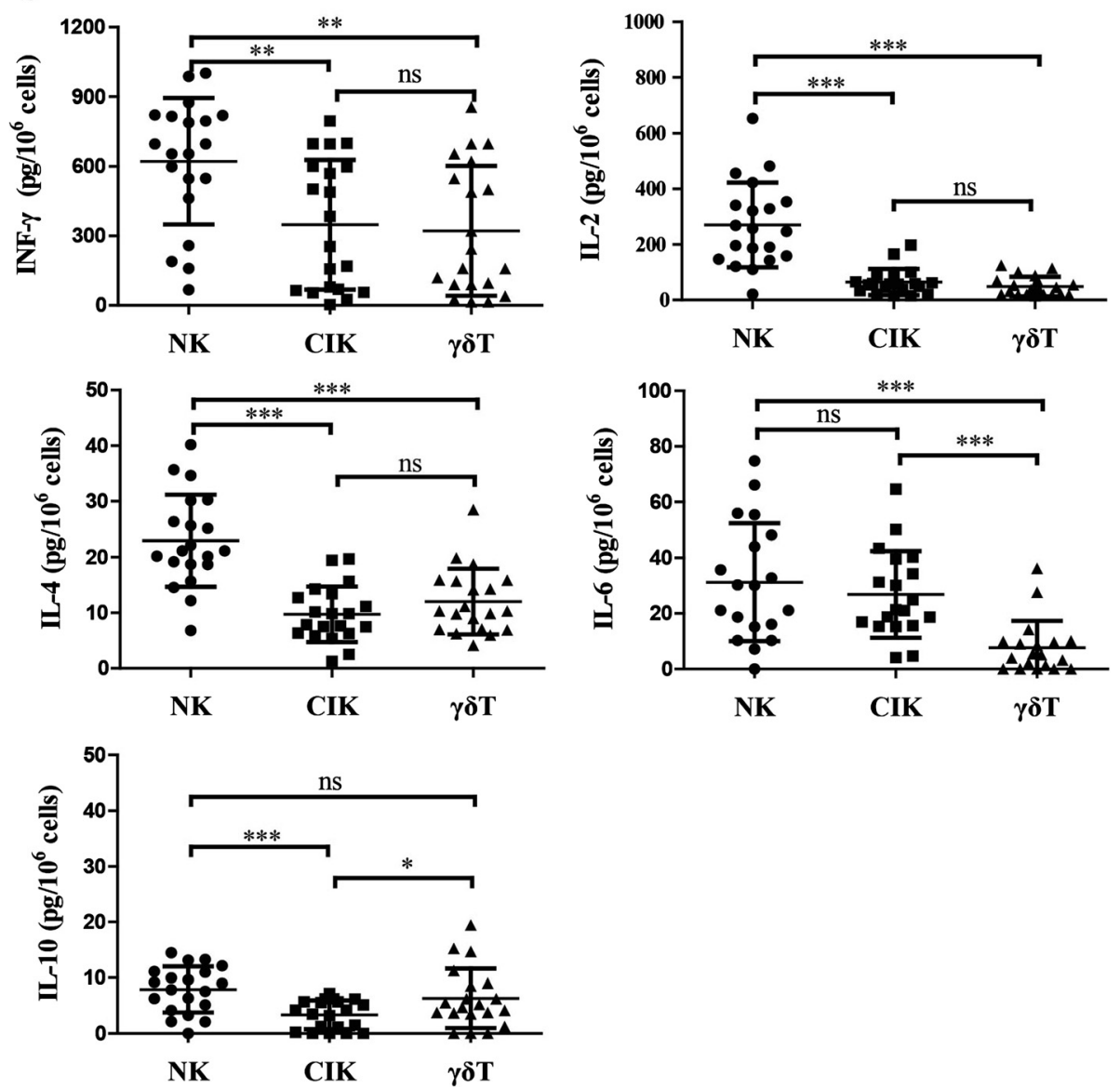

Fig. 5 Cytokine production in NK, CIK, and $\gamma \delta T$ cells. a Intracellular staining of IFN- $\gamma$ and IL-2 in NK, CIK, and $\gamma \delta$ T cells. Intracellular levels of IL-2 and IFN- $\gamma$ were measured as described for perforin and granzyme B detection. $\mathbf{b}$ Extracellular cytokine production of NK, CIK, and $\gamma \delta \mathrm{T}$ cells. The culture supernatants were collected and analyzed by ELISA for IFN- $\gamma$, IL-2, IL-4, IL-6, and IL-10. Results are expressed as the mean $\pm S D, n=20$. ${ }^{*} p<0.05$, ** $0.001<p<0.01,{ }^{* * *} p<0.001$, ns $p>0.05$

vitro using conventionally optimized methods. Although several studies have shown that CIK cells easily proliferate in vitro [25], our investigation shows that the proliferative ability of NK cells in our culture setup was superior to that of CIK cells. We also found that the ratios of NK, CIK, and $\gamma \delta$ T cells in the blood of cancer patients had no effect on their amplification efficiency. These results demonstrate that all three expanded immunocyte types have the potential for in vitro expansion to generate sufficient numbers for clinical applications.

The antitumor capacity of effector cells is another challenge in ACI. Our study assessed the phenotype, cytokine production, and cytotoxicity of the expanded cell types. Since NK, CIK, and $\gamma \delta$ T cells have shown significant efficacy in the treatment of hematological 

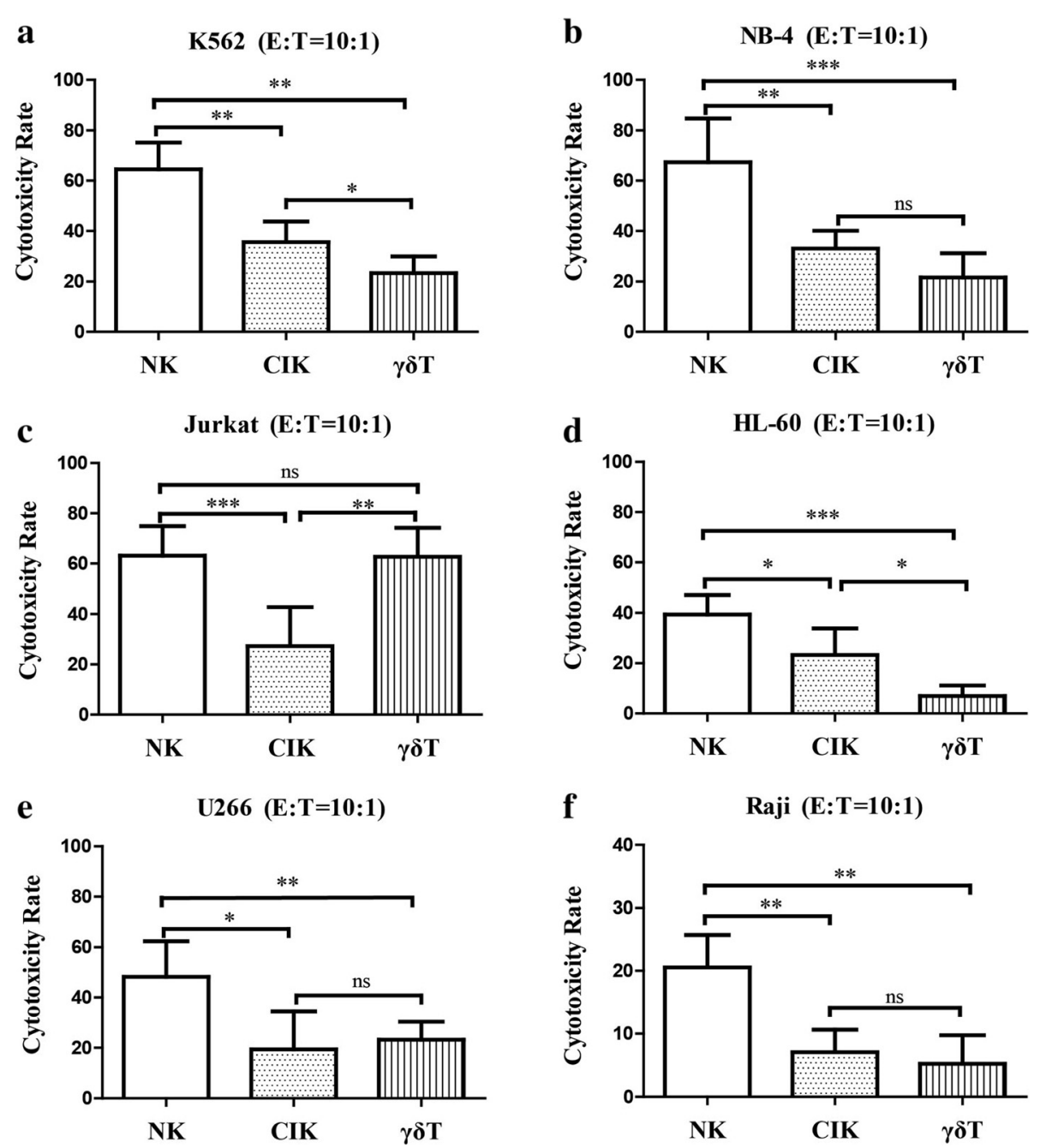

Fig. 6 Anti-tumor cytotoxicity of induced immune cells in vitro. Cytolysis against hematological malignancy targets K562 (a), NB-4 (b), Jurkat (c), HL-60 (d), U266 (e), and Raji (f) cells were compared at 10:1 effector-target ratios (E:T). NK cells showed the most significant cytotoxicity. Results are expressed as the mean $\pm \mathrm{SD}, n=20 .{ }^{*} p<0.05,{ }^{* *} 0.001<p<0.01$, ${ }^{* *} p<0.001, \mathrm{~ns} p>0.05$

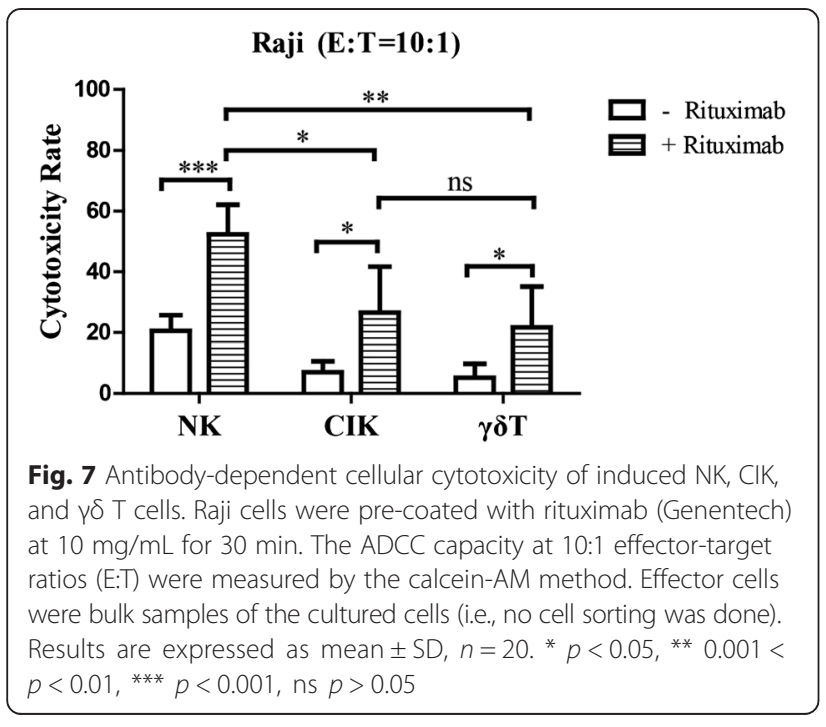

malignancies in vivo and in vitro, we selected leukemia and multiple myeloma cell lines as target cells for our analyses.

There are two main NK cell subsets distinguished by the level of CD56 expression in human blood, namely CD56 ${ }^{\text {dim }}$ and CD56 bright $[27]$. CD56 ${ }^{\text {dim }}$ cells are fully matured and strongly express CD16, a low-affinity Fc immunoglobulin $\mathrm{G}$ receptor that allows immune cells to participate in ADCC [10]. In contrast, CD56 ${ }^{\text {bright }}$ cells are more immature and are primarily considered to be cytokine producers with a limited role in cytolytic responses [28]. The NK cells expanded in this study had very high CD16 (Fig. 3b) and CD56 expression, and may represent a subset of NK cells undergoing differentiation. NK cells also express inhibitory and stimulatory receptors, such as killer immunoglobulin-like receptor (KIR), CD16, and NKG2D. The cytotoxic reactivity of 
NK cells results from the integration of signals from the stimulatory and inhibitory receptors as they engage ligands on the target cell surface. Our studies show that NK cells propagated in CD16 antibody-coated flasks exhibit increased expression of NKG2D and CD69, and decreased expression of inhibitory KIR. Intracellular and extracellular cytokine detection indicated that NK cells were more potent producers of IFN- $\gamma$ than $\mathrm{CIK}$ and $\gamma \delta$ $\mathrm{T}$ cells (Figs. 4a and 5e). IFN- $\gamma$ enhances antigen presentation by dendritic cells and stimulates production of the CXC chemokines MIG (CXCL9) and IP-10 (CXCL-10), which inhibit tumor angiogenesis and recruit CXCR3bearing effector cells to tumor sites $[29,30]$. Therefore, NK cells producing high amounts of IFN- $\gamma$ could contribute greatly to tumor regression during cancer immunotherapy.

Since induced immunocytes are usually used for ACI without purification, these cultured cells were directly harvested for cytotoxicity detection. In comparison to CIK and $\gamma \delta \mathrm{T}$ cells, the NK cells expanded in this study were significantly more cytotoxic toward many kinds of malignant cells lines including NK-resistant Raji cells (Fig. 6f). Raji cells normally elude NK cell recognition due to their expression of inhibitory KIR ligands (HLACw3 and HLA-Cw4) and a lack of NKG2D ligands (MICA) [31, 32]. The increased cytotoxic effects observed with our cultured NK cells likely result from their down-regulation of inhibitory KIR-CD158a and CD158b that engage HLA-Cw4 and HLA-Cw3, respectively.

ADCC is another mechanism by which cells convey antitumor activity, which is dependent on immunocyte CD16 expression. NK cells showed the highest expression of CD16 and the strongest ADCC efficacy in the presence of rituximab (Fig. 7). This implies that largescale NK cell expansion can promote the development of an effective combination therapy for cancer. While few differences were observed in ADCC function between $\mathrm{CIK}$ and $\gamma \delta \mathrm{T}$ cells, a significant difference in CD16 expression was detected between $\mathrm{CD}^{+} \mathrm{CD}^{+} 6^{+} \mathrm{CIK}$ and $\gamma \delta \mathrm{T}$ cells. Interestingly, CIK cells displayed a stronger cytotoxic effect toward K562 and HL-60 cells than $\gamma \delta \mathrm{T}$ cells, in contrast to our observations in Jurkat cells.

\section{Conclusions}

In this study, we established a cytokine-based expansion system for NK cells with the aim of developing them for clinical application. NK cells not only have a higher expansion capacity, but also much stronger antitumor activity in cytokine production, director cytotoxicity, and ADCC effect. Our analyses found that NK cells exhibit stronger cytotoxicity against lymphoma, leukemia, and myeloma cells than expanded CIK and $\gamma \delta$ T cells. Therefore, our study provides ex vivo evidence for the direct comparison of $\mathrm{NK}, \mathrm{CIK}$, and $\gamma \delta$ T cells. We also provide experimental evidence for their clinical application in hematological malignancies.

\section{Methods}

\section{Cells and culture}

Human leukemia (K562, HL-60, NB4, and Jurkat) cells, multiple myeloma (U266) cells, and lymphoma (Raji) cells were cultured in RPMI-1640 medium (Gibco, USA) supplemented with $10 \%$ heat-inactivated fetal bovine serum (Gibco), $100 \mathrm{U} / \mathrm{mL}$ penicillin, and $100 \mathrm{mg} / \mathrm{mL}$ streptomycin (Invitrogen, USA) at $37{ }^{\circ} \mathrm{C}$ in a humidified $5 \% \mathrm{CO}_{2}$ incubator.

\section{Isolation of peripheral blood mononuclear cells}

Heparinized peripheral blood samples were obtained from 20 volunteer cancer patients. Blood samples were centrifuged at $1800 \times g$ for $10 \mathrm{~min}$ and plasma was transferred to new tubes. Peripheral blood mononuclear cells (PBMCs) were isolated by density gradient centrifugation using Ficoll (Nycomed Pharma AS, Norway) at $800 \times g$ for $30 \mathrm{~min}$.

\section{Expansion of NK, CIK, and $\gamma \delta$ T cells}

NK cells were expanded as described [33]. Briefly, PBMCs were resuspended in AIM-V (Invitrogen) medium with $5 \%$ auto-plasma, $500 \mathrm{U} / \mathrm{mL}$ IL-2, $2 \mathrm{ng} / \mathrm{mL}$ IL-15 (both from Miltenyi Biotec, Germany), and $1 \mu \mathrm{g} / \mathrm{mL}$ OK432 (Shandong Luya Pharmaceutical Co., China) at a concentration of $1 \times 10^{6}$ cells $/ \mathrm{mL}$. PBMCs were cultured in flasks coated with anti-CD16 (Beckman, USA) for $24 \mathrm{~h}$ at $39{ }^{\circ} \mathrm{C}$ in a humidified $5 \% \mathrm{CO}_{2}$ atmosphere. The cells were cultured in AIM-V medium supplemented with $5 \%$ autoplasma, $1000 \mathrm{U} / \mathrm{mL} \mathrm{IL-2,} \mathrm{and} 2 \mathrm{ng} / \mathrm{mL}$ IL- 15 at $37^{\circ} \mathrm{C}$ for the next 13 days.

To generate CIK cells, PBMCs were cultured in AIM-V medium with $5 \%$ auto-plasma at $37{ }^{\circ} \mathrm{C}$ with $1000 \mathrm{U} / \mathrm{mL}$ IFN- $\gamma$ (Miltenyi Biotec). After $24 \mathrm{~h}, 100 \mathrm{ng} / \mathrm{mL}$ mouse anti-human CD3 monoclonal antibody (Peprotech, USA), $1000 \mathrm{U} / \mathrm{mL} \mathrm{IL}-2$, and $1000 \mathrm{U} / \mathrm{mL}$ IL-1 $\alpha$ (Miltenyi Biotec) were added. Fresh complete medium and IL-2 supplement $(1000 \mathrm{U} / \mathrm{mL})$ were added every three days.

To amplify $\gamma \delta \mathrm{T}$ cells, PBMCs were cultured in complete medium with $1 \mu \mathrm{M}$ zoledronate (Zoledronic Acid, Jilin Province Xidian Pharmaceutical Sci-Tech Development Co., China) and $400 \mathrm{U} / \mathrm{mL}$ human IL-2. Fresh complete medium and IL-2 supplement $(400 \mathrm{U} / \mathrm{mL})$ were added every 2 or 3 days.

\section{Quantification}

Cell expansion was expressed as "fold expansion," which was calculated by dividing the absolute output number of NK, CIK, and $\gamma \delta$ T cells after 14 days of culture by their number on day 0 . Absolute output numbers of these three immune cells were calculated by multiplying 
the total number of viable cells by the percentages of these three immune cells as determined by flow cytometry. Total viable numbers of $\mathrm{NK}, \mathrm{CIK}$, and $\gamma \delta$ $\mathrm{T}$ cells were determined by the CASY cell counter (BioSurplus, USA).

\section{Immunophenotyping}

The cultures were collected, washed, incubated for $15 \mathrm{~min}$ with mouse mAbs against human CD3-PerCP, CD56FITC, or PE, CD69-APC, CD16-PE (BD Biosciences, USA), and NKG2D-PE (BioLegend, USA). NK cells were incubated with CD158a-PE and CD158b-PE (BD Pharmingen, USA), CIK cells were incubated with CD4-PE and CD8-APC (BD Biosciences) and $\gamma \delta$ T cells were incubated with Vy9-FITC (BD Pharmingen), CD4-PE, and CD8-APC. Isotype-matched antibodies were used as controls. Perforin and granzyme B detection was performed according to the BD Cytofix/Cytoperm ${ }^{\text {Th }}$ Kit manual (BD Biosciences). Briefly, NK, CIK, and $\gamma \delta$ T cells were harvested and adjusted to $1 \times 10^{6}$ cells $/ \mathrm{mL}$ in RPMI-1640 medium containing $10 \%$ fetal calf serum, and incubated $0.1 \%$ GolgiStop (BD Biosciences) for $4 \mathrm{~h}$. After preincubation with $10 \%$ normal human serum, cells were stained with mAbs to identify $\mathrm{NK}\left(\mathrm{CD}^{-} \mathrm{CD} 56^{+}\right)$, CIK $\left(\mathrm{CD}^{+} \mathrm{CD} 56^{+}\right)$, and $\gamma \delta \mathrm{T}$ cells $\left(\mathrm{CD}^{+} \mathrm{V} 9^{+}\right)$, followed by intracellular staining for perforin-PE and granzyme B-PE (BD Pharmingen), and the corresponding isotype antibodies to determine intracellular cytokine levels.

Flow cytometry data acquisition was performed on a BD FACS Calibur (BD Biosciences) with Cell Quest Pro software. Analysis was performed with FlowJo software (Tree Star, USA).

\section{Cytokine secretion analysis}

$\mathrm{NK}, \mathrm{CIK}$, and $\gamma \delta \mathrm{T}$ cells were collected and suspended $\left(1 \times 10^{6}\right.$ cells $\left./ \mathrm{mL}\right)$ in AIM-V medium and incubated at $37{ }^{\circ} \mathrm{C}$ for $24 \mathrm{~h}$ in a humidified atmosphere of $5 \% \mathrm{CO}_{2}$. Supernatants were collected for detection of IFN- $\gamma$, IL-2, IL-4, IL-6, and IL-10. Cytokine secretion was quantified using commercially available enzyme-linked immunosorbent assay (ELISA) kits. Intracellular cytokine levels of IL-2 and IFN- $\gamma$ were measured as described above for perforin and granzyme B.

\section{Cytotoxicity analysis}

$\mathrm{NK}, \mathrm{CIK}$, and $\gamma \delta \mathrm{T}$ cells were used as the effectors and leukemia cells (K562, HL-60, NB-4, and Jurkat), lymphoma cells (Raji), and multiple myeloma cells (U266) were used as targets. Briefly, target cells were collected, washed once with PBS, and suspended in PBS at $1 \times 10^{6}$ cells $/ \mathrm{mL}$. Calcein-AM was added to a final concentration of $1 \mu \mathrm{M}$. Cells were incubated in a humidified atmosphere of $5 \% \mathrm{CO}_{2}$ for $30 \mathrm{~min}$ and then washed twice with PBS. For antibody-dependent cellular cytotoxicity
(ADCC) assays, Raji cells were pre-coated with rituximab (Roche, Switzerland) at $10 \mathrm{mg} / \mathrm{mL}$ for $30 \mathrm{~min}$. Effector cells were bulk samples of the cultured cells, i.e., no cell sorting was done. Lysis of the target cells by effector cells was assessed by Calcein release assay at a 10:1 effector-target ratio (E:T). After $4 \mathrm{~h}$ incubation, calcein release in the supernatant was assessed on a BioTek Synergy HT Microplate Reader (BioTek Instruments, USA). The percentage Calcein release was calculated according to the formula: $\%$ specific release $=[$ (experimental release - spontaneous release)/(maximum release - spontaneous release) $] \times 100 \%$.

\section{Statistical analysis}

Flow cytometry data were collected before and after induction and analyzed for correlation using Spearman's test. Other data were analyzed by Wilcoxon's rank-sum test in SPSS13.0 software. Results were considered significant at $\mathrm{p} \leq 0.05$.

\section{Informed consent/patient enrollment}

In this study, 20 tumor patients were enrolled. Informed consent in accordance with the Declaration of Helsinki was obtained from all patients, and approval was obtained from the Ethics Committee of the the First Hospital of Jilin University (protocol \#2010-019).

Table 1 Clinicla data of the patients in the study

\begin{tabular}{|c|c|c|c|c|}
\hline Patients no. & Gender & Age & Type of tumor & Stages of disease \\
\hline 1 & Female & 36 & Gastric Cancer & $\mathrm{IB}(\mathrm{T} 2 \mathrm{NOMO})$ \\
\hline 2 & Male & 65 & Gastric Cancer & IV(T4bNOM1) \\
\hline 3 & Male & 80 & Gastric Cancer & IV (rcTxNxM1) \\
\hline 4 & Female & 71 & Gastric Cancer & ॥A (T3NOMO) \\
\hline 5 & Female & 39 & Gastric Cancer & IIB (T1bN3aM0) \\
\hline 6 & Male & 66 & Kidney Cancer & (T1aNxMx) \\
\hline 7 & Male & 62 & Kidney Cancer & (T4NxMO) \\
\hline 8 & Female & 59 & Breast Cancer & IV (pT1N1M1) \\
\hline 9 & Female & 49 & Breast Cancer & I (pT1NOMO) \\
\hline 10 & Female & 49 & Breast Cancer & I (pT1cNOMO) \\
\hline 11 & Female & 56 & Breast Cancer & I (pT1NOMO) \\
\hline 12 & Male & 61 & Liver Cancer & $\mathrm{C}(\mathrm{BCLC})$ \\
\hline 13 & Male & 71 & Liver Cancer & $\begin{array}{l}\text { IV (Intrahepatic } \\
\text { cholangiocellular } \\
\text { carcinoma) }\end{array}$ \\
\hline 14 & Male & 80 & Liver Cancer & Early A (BCLC) \\
\hline 15 & Female & 63 & Lung Cancer & IB (pT2aNOMO) \\
\hline 16 & Male & 50 & Lung Cancer & IIIA (pT2aN2M0) \\
\hline 17 & Male & 43 & Lung Cancer & IB (pT2NOMO) \\
\hline 18 & Male & 68 & Lung Cancer & IIB (pT3NOMO) \\
\hline 19 & Female & 56 & Lung Cancer & (pTisNoMo) \\
\hline 20 & Female & 69 & Lung Cancer & Extended stage \\
\hline
\end{tabular}


Inclusion criteria were no radiation or chemotherapy for at least one month before blood collection. Only patients with solid tumors were included. Patient characteristics are listed in the Table 1.

\section{Competing interests}

The authors declare that they have no competing interests.

\section{Authors' contributions}

$\mathrm{CN}$ and HFJ contributed equally to this manuscript. CN conceived, designed, and carried out the studies and drafted the manuscript. HFJ and WL participated in the design of the study. JWC conceived and designed the study and revised and edited the manuscript. ML, JTX, and DSX carried out part of the studies. JFH revised and edited the manuscript. HH performed statistical analyses. All authors read and approved the final manuscript.

\section{Acknowledgments}

This work was supported in part by grants from National Science Foundation for Young Scholars (30901702), National Natural Science Foundation of China (31470798), Ministry of Education Key Project of Science and Technology (311015), National Major Scientific and Technological Special Project for Significant New Drugs Development during the Twelfth Five-year Plan Period (2013ZX09102032), Provincial Science Fund of Jilin Provincial Department of Finance (3D5116523428, 20150204027YY), and Norman Bethune Program of Jilin University (2012202).

Received: 6 January 2015 Accepted: 29 September 2015

\section{Published online: 12 October 2015}

\section{References}

1. Helmy KY, Patel SA, Nahas GR, Rameshwar P. Cancer immunotherapy: accomplishments to date and future promise. Ther Deliv. 2013;4(10):1307-20.

2. Wang ZX, Cao JX, Wang M, Li D, Cui YX, Zhang XY, et al. Adoptive cellular immunotherapy for the treatment of patients with breast cancer: A meta-analysis. Cytotherapy. 2014:16:934-45.

3. Farnault L, Sanchez C, Baier C, Le Treut T, Costello RT. Hematological malignancies escape from NK cell innate immune surveillance: mechanisms and therapeutic implications. Clin Dev Immunol. 2012;2012:421702.

4. von Lilienfeld-Toal M, Sievers E, Bodemuller V, Mihailescu C, Marten A, Gorschluter M, et al. Coculture with dendritic cells promotes proliferation but not cytotoxic activity of gamma/delta T cells. Immunol Lett. 2005;99(1):103-8.

5. Himoudi N, Morgenstern DA, Yan M, Vernay B, Saraiva L, Wu Y, et al. Human gammadelta T lymphocytes are licensed for professional antigen presentation by interaction with opsonized target cells. J Immunol. 2012;188(4):1708-16.

6. Verneris MR, Karami M, Baker J, Jayaswal A, Negrin RS. Role of NKG2D signaling in the cytotoxicity of activated and expanded CD8+ T cells. Blood. 2004;103(8):3065-72.

7. Verneris MR, Ito M, Baker J, Arshi A, Negrin RS, Shizuru JA. Engineering hematopoietic grafts: purified allogeneic hematopoietic stem cells plus expanded CD8+ NK-T cells in the treatment of lymphoma. Biol Blood Marrow Transplant. 2001;7(10):532-42.

8. Fisher JP, Heuijerjans J, Yan M, Gustafsson K, Anderson J. Gammadelta T cells for cancer immunotherapy: a systematic review of clinical trials. Oncoimmunology. 2014;3(1), e27572.

9. Terme M, Ullrich E, Delahaye NF, Chaput N, Zitvogel L. Natural killer cell-directed therapies: moving from unexpected results to successful strategies. Nat Immunol. 2008;9(5):486-94.

10. Campbell KS, Hasegawa J. Natural killer cell biology: an update and future directions. J Allergy Clin Immunol. 2013;132(3):536-44.

11. Orange JS. Human natural killer cell deficiencies. Curr Opin Allergy Clin Immunol. 2006;6(6):399-409.

12. Imai K, Matsuyama S, Miyake S, Suga K, Nakachi K. Natural cytotoxic activity of peripheral-blood lymphocytes and cancer incidence: an 11-year follow-up study of a general population. Lancet. 2000:356(9244):1795-9.

13. Miller JS, Soignier Y, Panoskaltsis-Mortari A, McNearney SA, Yun GH, Fautsch SK, et al. Successful adoptive transfer and in vivo expansion of human haploidentical NK cells in patients with cancer. Blood. 2005;105(8):3051-7.
14. Rubnitz JE, Inaba H, Ribeiro RC, Pounds S, Rooney B, Bell T, et al. NKAML: a pilot study to determine the safety and feasibility of haploidentical natural killer cell transplantation in childhood acute myeloid leukemia. J Clin Oncol. 2010;28(6):955-9.

15. Schmidt-Wolf IG, Negrin RS, Kiem HP, Blume KG, Weissman IL. Use of a SCID mouse/human lymphoma model to evaluate cytokine-induced killer cells with potent antitumor cell activity. J Exp Med. 1991;174(1):139-49.

16. Wang Y, Bo J, Dai HR, Lu XC, Lv HY, Yang B, et al. CIK cells from recurrent or refractory AML patients can be efficiently expanded in vitro and used for reduction of leukemic blasts in vivo. Exp Hematol. 2013;41(3):241-52. e243.

17. Locatelli F, Merli P, Rutella S. At the Bedside: Innate immunity as an immunotherapy tool for hematological malignancies. J Leukoc Biol. 2013;94(6):1141-57.

18. Introna M, Golay J, Rambaldi A. Cytokine Induced Killer (CIK) cells for the treatment of haematological neoplasms. Immunol Lett. 2013;155(1-2):27-30.

19. Castella B, Vitale C, Coscia M, Massaia M. VgammagVdelta2 T cell-based immunotherapy in hematological malignancies: from bench to bedside. Cell Mol Life Sci. 2011;68(14):2419-32.

20. Gogoi D, Chiplunkar SV. Targeting gamma delta T cells for cancer immunotherapy: bench to bedside. Indian J Med Res. 2013;138(5):755-61.

21. Knorr DA, Bachanova V, Verneris MR, Miller JS. Clinical utility of natural killer cells in cancer therapy and transplantation. Semin Immunol. 2014;26(2):161-72.

22. Jiang J, Wu C, Lu B. Cytokine-induced killer cells promote antitumor immunity. J Transl Med. 2013;11:83.

23. Koepsell SA, Miller JS, McKenna Jr DH. Natural killer cells: a review of manufacturing and clinical utility. Transfusion. 2013;53(2):404-10.

24. Luhm J, Brand JM, Koritke P, Hoppner M, Kirchner H, Frohn C. Large-scale generation of natural killer lymphocytes for clinical application. J Hematother Stem Cell Res. 2002;11(4):651-7.

25. Imai C, Iwamoto S, Campana D. Genetic modification of primary natural killer cells overcomes inhibitory signals and induces specific killing of leukemic cells. Blood. 2005;106(1):376-83.

26. Sutlu T, Stellan B, Gilljam M, Quezada HC, Nahi H, Gahrton G, et al. Clinical-grade, large-scale, feeder-free expansion of highly active human natural killer cells for adoptive immunotherapy using an automated bioreactor. Cytotherapy. 2010;12(8):1044-55.

27. Caligiuri MA. Human natural killer cells. Blood. 2008;112(3):461-9.

28. Poli A, Michel T, Theresine M, Andres E, Hentges F, Zimmer J. CD56bright natural killer (NK) cells: an important NK cell subset. Immunology. 2009;126(4):458-65.

29. Maghazachi AA. Role of chemokines in the biology of natural killer cells. Curr Top Microbiol Immunol. 2010;341:37-58.

30. Schroder K, Hertzog PJ, Ravasi T, Hume DA. Interferon-gamma: an overview of signals, mechanisms and functions. J Leukoc Biol. 2004;75(2):163-89.

31. Hasenkamp J, Borgerding A, Wulf G, Uhrberg M, Jung W, Dingeldein S, et al. Resistance against natural killer cell cytotoxicity: analysis of mechanisms. Scand I Immunol. 2006;64(4):444-9.

32. Wang $Y$ P, Zhang $C$, Niu JF, Zhang JH, Xu XQ, Wang JF. [Expression and significance of NKG2D ligands in 13 tumor cell lines]. Ai Zheng. 2008;27(3):243-8.

33. Cui J, Wang N, Zhao H, Jin H, Wang G, Niu C, et al. Combination of radiofrequency ablation and sequential cellular immunotherapy improves progression-free survival for patients with hepatocellular carcinoma. Int J Cancer J Int Du Cancer. 2014;134(2):342-51.

\section{Submit your next manuscript to BioMed Central and take full advantage of:}

- Convenient online submission

- Thorough peer review

- No space constraints or color figure charges

- Immediate publication on acceptance

- Inclusion in PubMed, CAS, Scopus and Google Scholar

- Research which is freely available for redistribution 